Article available at nttp://WwW.parasite-journal.org or nttp://dx.dol.org/10.1051/parasite/20000/3201

\title{
SARCOCYSTIS STENODACTYLICOLUBRIS N. SP., A NEW SARCOSPORIDIAN COCCIDIUM WITH A SNAKE-GECKO HETEROXENOUS LIFE CYCLE
}

\author{
MODRÝ D.,***, KOUDELA B.,*** \& ŠLAPETA J.R.**
}

Summary :

Oocysts/sporocysts of Sarcocystis sp. measuring $9.7(9-10) \times$ $7.6(7-8) \mu \mathrm{m}$ were found in the intestinal contents of the Dahl's whip snake Coluber najadum. Of wide spectrum of experimentally inoculated hosts, only species of the family Gekkonidae - Ptyodactylus guttatus and Stenodactylus grandiceps - were found to be susceptible intermediate hosts. Transparent, barely visible sarcocysts found in tail, limbs and tongue striated muscles of the geckoes were 175-200 $\mu \mathrm{m}$ $\times 35-50 \mu \mathrm{m}$ in size at $78 \mathrm{DPI}$. Ultrastructurally, the primary cyst wall was characteristic by spine-like villar protrusions up to $800 \mathrm{~nm}$ long, 200-250 nm in diameter at their base, tapering to thinner apex. Protrusions appear typically lobular or irregular in the cross-sections. Back-transmission from $P$. guttatus to Coluber rogersi leaded to oocysts/sporocysts excretion since 38 days post infection. Based on sarcocyst morphology and experimental data, Sarcocystis stenodactylicolubris is apparently a new species. Based on obtained and already published results, Sarcosporidia parasitising colubrid snakes as definitive hosts are suggested to be family specific on the level of their intermediate host.

KEY WORDS : Sarcocystis stenodactylicolubris n. sp., snake, gecko, life cycle.

\section{INTRODUCTION}

S nakes are often reported as definitive hosts of the coccidian genus Sarcocystis (e.g. Matuschka, 1985; McAllister et al., 1993, 1995, 1996; Paperna \& Finkelman, 1998; Upton et al., 1992). Seventeen Sarcocystis species are described with a full life cycle (Matuschka, 1987a; Odening, 1998; Šlapeta et al., 1999; Volf et al., 1999). Although some of these species use lizards of saurian families Lacertidae and Scincidae as intermediate hosts, no Sarcocystis cycling between snakes and geckoes (Gekkonidae) was described to date. However, a few records of sarcocysts from tissues of gekkonid lizards were reported (Bertram, 1892;

\footnotetext{
* Department of Parasitology, University of Veterinary and Pharmaceutical Sciences, Palackého 1-3, 61242 Brno, Czech Republic.

** Institut of Parasitology, Academy of Sciences of the Czech Republic, Branišovská 31, 37005 České Budějovice, Czech Republic. Correspondence: David Modrý.

Tel: +420-5-41562979 - Fax: +420-5-41562266.

e-mail: modryd@vfu.cz
}

Résumé : SARCOCYSTIS STENODACTYLICOLUBRIS N. SP., UNE NOUVELLE COCCIDIE PRÉSENTANT UN CYCLE HÉTÉROXÈNE SERPENT-GECKO

Des oocystes/sporocystes de Sarcocystis sp. mesurant 9,7 (9-10) $x$ 7,6 (7-8) $\mu \mathrm{m}$ ont été trouvés dans le contenu intestinal du serpent Coluber najadum. Expérimentalement, seules des espèces de la famille des Gekkonidae - Ptyodactylus guttatus et Stenodactylus grandiceps - se sont révélées être de possibles hôtes intermédiaires de ce parasite. Les sarcocystes transparents et à peine visibles, trouvés dans les muscles striés de la queve, des pattes et de la langue de ces geckos mesurent 175-200 $\mu \mathrm{m} x$ 35-50 $\mu \mathrm{m}$. Au niveau ultrastructural, la paroi externe du cyste est caractérisée par des protrusions villositaires ressemblant à des épines, de $800 \mathrm{~nm}$ de longueur, 200-250 nm de diamètre à leur base, et effilées à leur extrémité. En coupe, ces protrusions sont lobulées ou irrégulières. La transmission de Ptyodactylus guttatus à Coluber rogersi conduit à une élimination d'oocystes/sporocystes à partir du $38^{e}$ jour après l'infestation. La morphologie des sarcocystes et les données expérimentales font apparaître Sarcocystis stenodactylicolubris comme une nouvelle espèce.

MOTS CLÉS : Sarcocystis stenodactylicolubris n.sp., serpent, gecko, cycle parasitaire.

Chatton \& Avel, 1923; Dupouy \& Kechemir, 1973; Paperna \& Finkelman, 1998; Weber, 1909, 1910).

Presented paper provides the results of series of transmissional experiments with an isolate of Sarcocystis originated from a colubrid snake Coluber najadum. Furthermore, the endogenous developmental stages of this species are described within its intermediate (gecko) and final (colubrid snake) hosts after an experimental infection. Described Sarcocystis differs significantly from all hitherto described members of the genus and is therefore considered to be a new species.

\section{MATERIALS AND METHODS}

INFECTIOUS MATERIAL

A n adult, melanistic male of Dahl's whip snake, Coluber najadum (Eichwald, 1831) was collected in black lava desert near Ar Rashiedeh in SW Syria during the herpetological and parasitological field research in April 1994. Snake was trans- 
ported to the Department of Parasitology of University of Veterinary and Pharmaceutical Sciences, Brno, Czech Republic. The snake was kept in an isolated terrarium and force-fed with sucking laboratory mice. Fresh faecal samples were collected from terrarium and examined repeatedly using modified Sheater's sugar solution (s.g. 1.30) flotation technique. The snake was euthanized due to bad health status three weeks after importation and tissue samples were fixed for further examination. Sporocysts from the faeces and intestinal content were concentrated by flotation, examined morphologically and photographed using Nomarski interference contrast optics (NIC). Measurements were made using a calibrated ocular micrometer and are reported in micrometers, as means, followed by the ranges in parentheses. Sporocysts were stored at a temperature of $4-5^{\circ} \mathrm{C}$ in $2.5 \%(\mathrm{w} / \mathrm{v})$ aqueous potassium dichromate solution. Prior the inoculation sporocysts were washed in tap water and counted using haemocytometer.

\section{INFECTION}

\section{AND MAINTENANCE OF EXPERIMENTAL ANIMALS}

Following laboratory bred lizards, which can naturally occur in food spectrum of Coluber najadum in Syria, were used for intermediate host studies (numbers of infected and control animals used in experiments are noted in parentheses): Lacertidae: Acanthodactylus grandis $(2,1)$; Mesalina brevirostris $(2,1)$; Scincidae: Chalcides ocellatus (3, 2), Mabuya vittata (2, 1); Gekkonidae: Ptyodactylus guttatus (2, 1), Stenodactylus grandiceps $(1,1)$. All lizards were caged separately in plastic terraria and fed on laboratory reared crickets with mineral and vitamin supplementation. Each experimental lizard was inoculated orally with $2 \times 10^{5}$ sporocysts by a stomach tube. Additionally, five BALB/c mice and five laboratory reared common voles (Microtus arvalis) were infected orally with $10^{5}$ sporocysts and kept as described previously (Šlapeta et al., 1999). Experimentally inoculated and control lizards were euthanized by ether and dissected 78 days after the infection (DPI) and experimentally inoculated rodents were examined on 150 and 180 DPI, respectively.

In the definitive host study one adult, laboratory kept, coccidia free colubrid snake Coluber rogers $i$ was used. Snake was fed solely on laboratory mice. Faeces were monitored using flotation technique with negative result for 12 months prior the experimental infection. One living, captive born male of Ptyodactylus guttatus, inoculated orally with $2 \times 10^{5}$ sporocysts 80 days before, was fed to this snake. Terminal half of the tail of this gecko was biopsied two days before the feeding experiment for presence of sarcocysts in muscles. Faecal samples of inoculated snake were examined using flotation method for the presence of coccidia in intervals of 5-15 days, depending upon the irregular feeding habit of the snake.

\section{Histology}

At necropsies, following tissue samples were collected and fixed in $10 \%$ buffered formalin: naturally infected Coluber najadum - seven equidistantly spaced sections of the intestine; lizards - stomach, small intestine, large intestine, cloaca, heart, lung, liver, kidney, abdominal wall, tongue, biceps femoris muscle and tail; rodents - oesophagus, stomach, duodenum, middle jejunum, ileum, caecum, colon, rectum, heart, lungs, liver, spleen, kidney, urine bladder, tongue, diaphragm, heart, muscles of the abdominal wall, brachial muscles and left biceps femoris muscle. Tissue samples were consequently processed for the histology using standard methods. Paraffin sections were stained with haematoxylin and eosin ( $\mathrm{H} \& \mathrm{E})$ and Giemsa stains.

\section{ELECTRON MICROSCOPY}

Muscles of Stenodactylus grandiceps containing sarcocysts were fixed in $2.5 \%$ glutaraldehyde in cacodylate buffer $(0.1 \mathrm{M}, \mathrm{pH} 7.4)$ at $4^{\circ} \mathrm{C}$ and postfixed in $1 \%$ osmium tetroxide in the same buffer. Specimens were washed three times in the same buffer, dehydrated in graded alcohols and embedded in Durcupan. Ultrathin sections were stained with uranyl acetate and lead citrate and then examined with a JEOL 1010 transmission electron microscope.

Specimens for scanning electron microscopy (SEM) were fixed in $4 \%$ buffered paraformaldehyd at $4^{\circ} \mathrm{C}$. Small portions of tissue were rinsed several times in distilled water, dehydrated in alcohol and acetone series and desiccated by critical point drying in carbon dioxide. The samples were then gold-coated in spraying device and examined with a JEOL JMS 6300 scanning electron microscope.

\section{RESULTS}

\section{STAGES IN FOUND THE DEFINITIVE HOST}

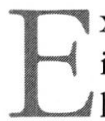
xamination of the intestinal content of naturally infected Coluber najadum revealed numerous liberated sporocysts of Sarcocystis sp. (Fig. 1). Oocysts were only rarely seen. Sporocysts are tetrazoic, ellipsoidal, $9.7(9-10) \times 7.6(7-8) \mu \mathrm{m}$, shape index 1.3. Stieda and substieda bodies are absent. Sporocyst residuum is present, composed of numerous small granules of the equal size. Sporocyst wall is single-layered, smooth and colourless; sporozoites are long oval. Numerous sporocysts, structurally and morphologically identical with the original isolate, were first found on 39 DPI in faeces of experimentally infected Coluber 
rogersi. Only few oocysts (less than $1 \%$ ) were observed, having thin, colourless oocyst wall closely adjacent to the two fully sporulated sporocysts. Shedding of the oocysts/sporocysts by experimentally infected Coluber rogersi lasted at least for three consequent months.

Histological examination of naturally infected Coluber najadum revealed greatly thickened oedematous lamina propria of the proximal part of intestine. The lamina propria was packed with bisporocystic oocysts (Fig. 7) which mostly collapsed during the previous fixation and processing, similar findings were obtained using SEM of the cross-section through intestinal mucosa (Fig. 9). However, the majority of stages was lost during the sample processing and mostly only hollows in mucosa indicated the previous location of oocysts/sporocysts (Figs 9, 10). SEM photographs of the mucosal surface revealed areas of extensive erosions with liberating sporocysts, organised usually in clusters (Figs 8,11). Distinct sutures connecting plates of sporocyst wall appeared on detailed SEM photographs of sporocysts surface (Fig. 12).

\section{STAGES IN EXPERIMENTAL INTERMEDIATE HOSTS, SARCOCYST MORPHOLOGY}

Lizards of seven species, belonging to three families and two species of rodents were inoculated with the original isolate from naturally infected Coluber najadum (Table I). Only geckoes Stenodactylus grandiceps and Ptyodactylus guttatus proved susceptible to the infection. Numerous sarcocysts were observed in wet smears squeezed under a cover glass as well as in histological sections of musculature of tail, limbs and tongue of all infected geckos. Sarcocysts were not observed in the musculature of any other lizards nor rodents. Neither clinical signs nor mortality were observed in experimentally infected hosts.

\begin{tabular}{cccc}
\hline $\begin{array}{c}\text { Experimentaly } \\
\text { inoculated host }\end{array}$ & $\begin{array}{c}\text { Infectious } \\
\text { dose } \\
\text { (sporocysts) }\end{array}$ & $\begin{array}{c}\text { Euthanized } \\
\text { (DPI) }\end{array}$ & $\begin{array}{c}\text { Result } \\
\text { (+/-) }\end{array}$ \\
\hline $\begin{array}{c}\text { Stenodactylus grandiceps } \\
\text { (Gekkonidae) }\end{array}$ & $2 \times 10^{5}$ & 78 & + \\
$\begin{array}{c}\text { Ptyodactylus guttatus } \\
\text { (Gekkonidae) }\end{array}$ & $2 \times 10^{5}$ & 78 & + \\
$\begin{array}{c}\text { Mesalina abrevirostris } \\
\text { (Lacertidae) }\end{array}$ & $2 \times 10^{5}$ & 78 & - \\
$\begin{array}{c}\text { Acanthodactylus grandis } \\
\text { (Lacertidae) }\end{array}$ & $2 \times 10^{5}$ & 78 & - \\
$\begin{array}{c}\text { Mabuya vittata } \\
\text { (Scincidae) }\end{array}$ & $2 \times 10^{5}$ & 78 & - \\
$\begin{array}{c}\text { Chalcides ocellatus } \\
\text { (Scincidae) }\end{array}$ & $2 \times 10^{5}$ & 78 & - \\
Microtus arvalis \\
$\quad$ (Cricetidae) \\
$\begin{array}{c}\text { Mus BAL/c } \\
\text { (Muridae) }\end{array}$ & $1 \times 10^{5}$ & 120 & - \\
\hline$\quad$ & $1 \times 10^{5}$ & 180 & - \\
\hline
\end{tabular}

Table I. - Intermediate host experiments.
Sarcocysts found in $S$. grandiceps 78 DPI were elongate, reached a length of $175-200 \mu \mathrm{m}$ and a width of $35-50 \mu \mathrm{m}$. When studied with the light microscope, the primary cyst wall of sarcocysts was about $1-2 \mu \mathrm{m}$ thick, with barely visible villar protrusions (Fig. 2). Secondary cyst wall was not observed. Elongated cystozoites, 5-6 $\times 1.5 \mu \mathrm{m}$ with centrally located nucleus were observed inside cysts, together with few scattered metrocytes.

Ultrastructurally, the sarcocyst wall belongs to the type II. according Dubey et al. (1989). There were characteristic spine-like villar protrusions arising from the cyst wall. Ground substance was ca. 200-300 nm thick with numerous septa stretched dividing the cyst into compartments containing cystozoites (Fig. 5). Protrusions are up to $800 \mathrm{~nm}$ long, $200-250 \mathrm{~nm}$ in diameter at their base, tapering to thinner apex, ca $100 \mu \mathrm{m}$ in diameter. The wall of protrusions appeared slightly undulated in longitudinal sections. Protrusions are typically lobular or irregular in the cross-sections, mainly at the basis (Fig. 6). Endodyogony (Fig. 4) was the only reproduction mode observed within examined sarcocysts. Sarcocysts observed in experimentally infected Ptyodactylus guttatus 78 DPI were morphologically identical to that reported above.

\section{TAXONOMIC SUMMARY}

\section{Sarcocystis stenodactylicolubris n. sp.}

Exogenous stages: Oocysts only rarely seen, fully sporulated free sporocysts represent a majority of stages found in the faeces. Sporocysts tetrazoic, ellipsoidal, $9.7(9-10) \times 7.6(7-8) \mu \mathrm{m}$. Sporocyst residuum present, composed of numerous small granules of the equal size. Sporocyst wall single-layered, smooth and colourless, with distinct sutures observed by SEM; sporozoites elongately oval.

Sarcocysts: Sarcocysts are elongated, 78 DPI are 175$200 \mu \mathrm{m}$ long and 35-50 $\mu \mathrm{m}$ wide. Sarcocyst wall type II. according Dubey et al. (1989). Primary sarcocyst wall ca. $2 \mu \mathrm{m}$ thick, with numerous spine-like villar protrusions, lobular or irregular in the cross-section.

Type host: Dahl's whip snake, Coluber najadum (Eichwald, 1831) (Serpentes: Colubridae).

Other hosts: Coluber rogersi (Anderson, 1893) (final, experimentally infected); Stenodactylus grandiceps Haas, 1952; P. guttatus Heyden, 1827 (intermediate, all infected experimentally).

Type locality: Ar Rashiedeh, SW Syria ( $\left.32^{\circ} 40^{\prime} \mathrm{N}, 37^{\circ} 3^{\prime} \mathrm{E}\right)$

Type specimens: Photosyntypes and histological slides are deposited in Parasitological Institute of Academy of Sciences of the Czech Republic in České Budějovice, coll. No. R 181/94.

Symbiotypes: Symbiotype of the type host (alcohol preserved) is deposited in the Herpetological collec- 

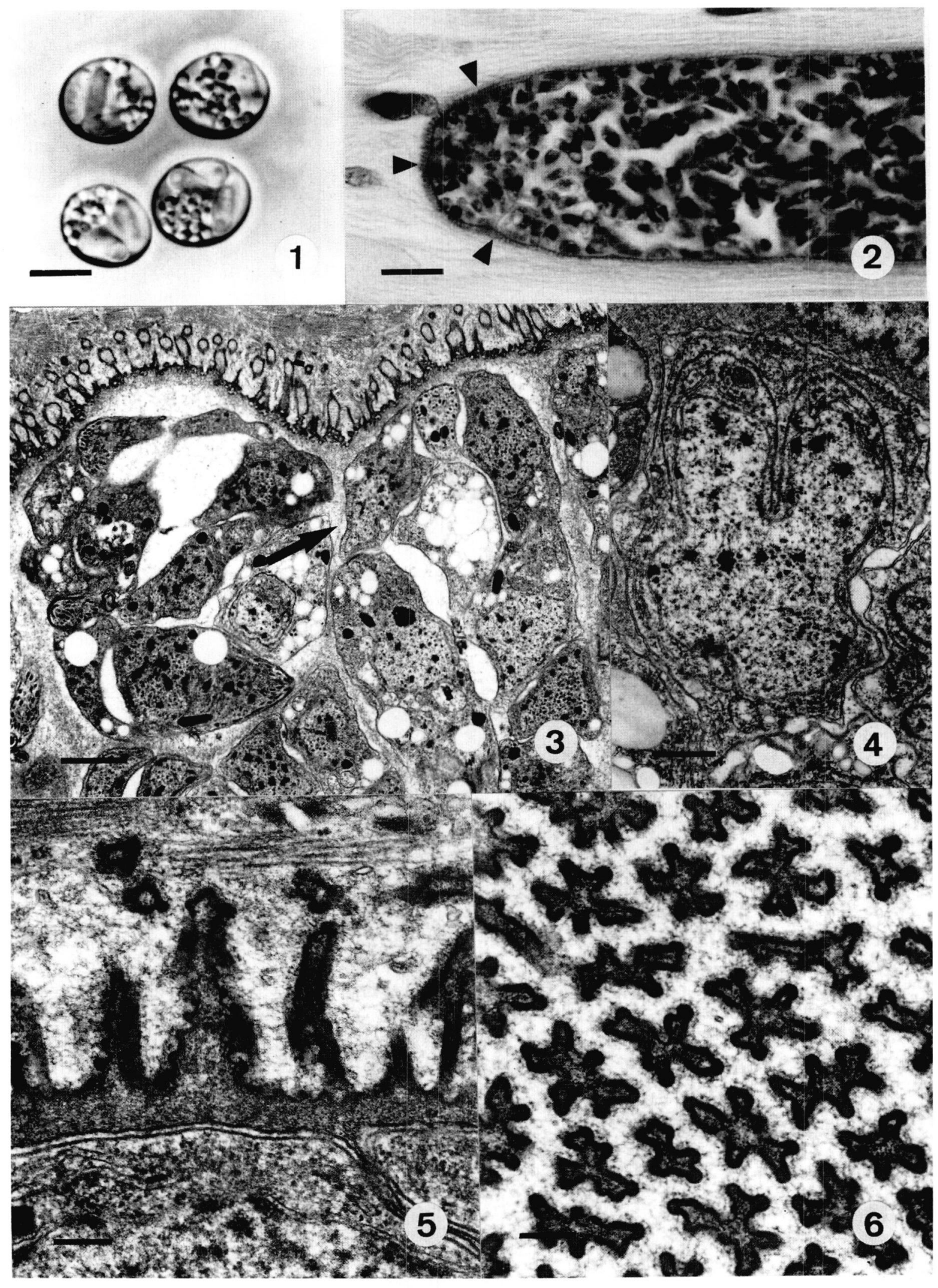

Figs 1-6. - Basic morphological features of Sarcocystis stenodactylicolubris sp. n. Fig. 1. Sporocysts isolated from faeces of C. najadum, scale bar $=5 \mu \mathrm{m}$. Fig. 2. Histological section of the tail musculature of $S$. grandiceps with sarcocyst, note barely visible villar protrusions (arrowheads). Fig. 3. Ultrastructure of sarcocyst of Sarcocystis stenodactylicolubris showing several cystozoites, septa and protrusions. Fig. 4. Cystozoites dividing by the endodyogony. Fig. 5. Spine-like villar protrusions of the primary cyst wall, scale bar $=200 \mathrm{~nm}$. Fig. 6 . Crosssection through the zone of protrusions showing their lobular character. 


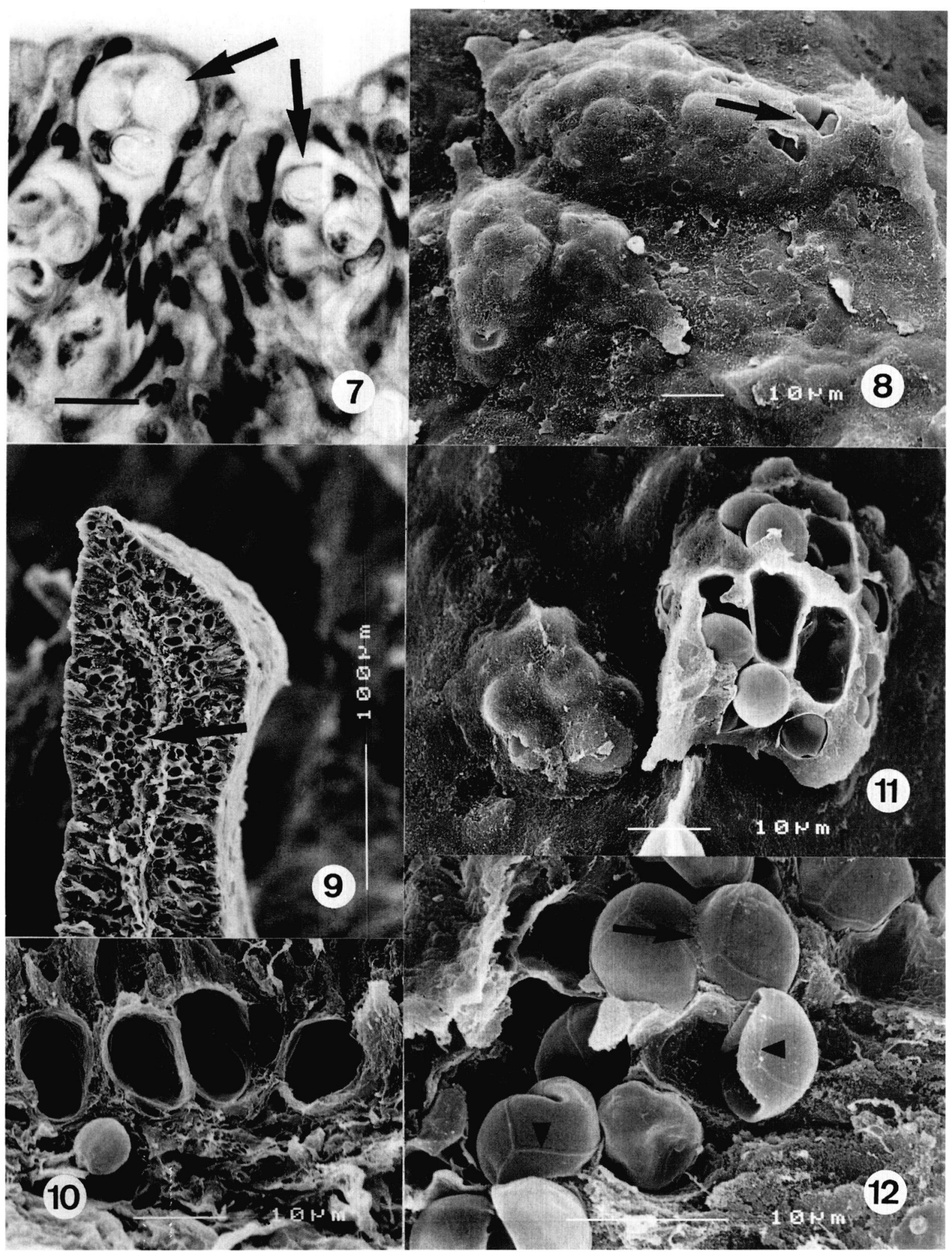

Figs 7-12. - Developmental stages of Sarcocystis stenodactylicolubris sp. n. in Coluber najadum. Fig. 7. Histological section of intestinal mucosa with oocysts/sporocysts (arrows), scale bar $=10 \mu \mathrm{m}$. Fig. 8. SEM picture of mucosal surface showing erosions with liberating sporocysts (arrow). Fig. 9. SEM picture of cross section through intestinal mucosa with numerous hollows indicating previous location of developmental stages (arrow). Fig. 10. Detail view of the same region. Fig. 11. Sporocysts liberating in clusters from erosions in the mucosal surface. Fig. 12. Oocyst (arrow) and sporocysts liberated from the intestinal mucosa. Note rib-like prominating sutures of plates of sporocyst wall (arrowheads). 
tion of the National Museum Prague, coll. No. NMP6W34896.

Etymology: The specific name stenodactylicolubris reflects the generic name of the intermediate (Stenodactylus) and definitive host (Coluber).

\section{DISCUSSION}

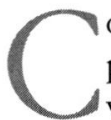
occidia of the genus Sarcocystis are common parasites among snakes of family Colubridae, which serve as definitive hosts (Matuschka, 1985, 1987a; McAllister et al., 1993, 1995; Paperna \& Finkelman, 1998; Roudabush, 1937; Volf et al., 1999). In contrast to common findings of these parasites in colubrids, only six species were described with their life cycle up to date (Bledsoe, 1980; Matuschka, 1981, 1986, 1987b; Sakran, 1993; Volf et al., 1999). Various lizards are intermediate hosts of four of these species, which are therefore compared with Sarcocystis stenodactylicolubris sp. $\mathrm{n}$.

Sarcocystis gongyli Trinci 1911 is described from colubrid snake Spalerosophis diadema and scincid intermediate host Chalcides ocellatus (Abdel-Ghaffar et al., 1990; Sakran, 1993, Trinci, 1911). Sarcocysts of this species differ significantly from $S$. stenodactylicolubris in having leaf-like protrusions (Bashtar et al., 1991).

Sarcocystis chalcidicolubris Matuschka 1987 described from the Mediterranean region uses also colubrid snake, namely Coluber ravergieri as definitive hosts and skink Chalcides ocellatus as intermediate hosts. S. stenodactylicolubris can be differentiated well from this species ultrastructurally by different protrusions.

Similarly, Sarcocystis podarcicolubris Matuschka, 1981 from colubrid snakes of the genus Coluber and Macroprotodon and from lacertids belonging to genera Lacerta, Podarcis and Algyroides differs significantly in ultrastructural features of sarcocysts. Protrusions of S. podarcicolubris are described as palisade-like (Matuschka et al., 1984), in contrast to villar, spine-like protrusions of $S$. stenodactylicolubris.

Sarcocystis lacertae Babudieri, 1932 cycles between colubrid snake Coronella austriaca and lizards Podarcis muralis. Also this species differs significantly in its ultrastructure, having spine-like, typically arching protrusions with spongiform appearance of the ground substance (Volf et al., 1999).

A few records of sarcocysts from tissues of gekkonid lizards are reported to date. Bertram (1892) had described Sarcocystis platydactyli from Mediterranean gecko Tarentola mauritanica. Later on, several authors reported tissue cysts in this common Mediterranean gecko (Weber, 1909, 1910; Chatton \& Avel, 1923; Dupouy \& Kechemir, 1973). However, tissue cysts reported by all of these authors are typical in having thick sarcocyst wall and belong evidently to a species different from S. stenodactylicolubris. The final host of $S$. platydactyli remains unknown and needs further research. Recently, Paperna \& Finkelman (1998) reported presence of sarcocysts in tissues of Ptyodactylus hasselquistii from Israel. Ultrastructurally, sarcocysts presented by these authors differs in having undulating, spongiforme-like ground substance with numerous fine invaginations and protrusions with only slightly undulating circumference in cross-section. Majority of snakes of the genus Coluber is typically saurophagous, feeding on wide variety of lizards. In many ecosystems they have opportunity to feed on saurians of families Scincidae, Gekkonidae and Lacertidae. However, the composition of their prey differs greatly based on the snake species, type of the habitat and the season. Geckoes of genera Stenodactylus and Ptyodactylus are the most common saurian species in black lava desert of southern Syria and their involvement in the life cycle of Sarcocystis species is therefore not surprising. Possibly, more species of Sarcocystis can occur together in colubrid snakes of the region, using also scincids and lacertids as intermediate hosts. Based on results of our experiments and on previously published data we can suggest that sarcosporidia parasitising colubrid snakes as final hosts are family specific on the level of their intermediate hosts, usually transmissible to more host genera.

Pathogenicity and pathology of Sarcosporidia in final ophidian hosts was only scarcely reported. Our findings in the intestine of naturally infected Coluber najadum are similar to that published by Daszak \& Cunningham (1995) in Pituophis melanoleucus. Similarly, the absence of clinical and pathological findings in infected intermediate hosts corresponds well with previously published studies (Matuschka, 1981, 1985, 1987a; Volf et al., 1999).

Sporocysts wall composed of four collapsible plates joined in rib-like prominating sutures was repeatedly reported in members of genera Isospora, Toxoplasma and Sarcocystis (Box et al., 1980; Speer et al., 1973, 1976). Our results showing sporocysts surface of S. stenodactylicolubris using SEM are identical and confirm this feature to be a common feature for Sarcocystis spp. Based on all morphological and biological differences reported in this study it is evident, that Sarcocystis stenodactylicolubris represents a new species.

\section{ACKNOWLEDGEMENTS}

W e are indebted to J. Moravec for confirming the snake determination and M. Modry and H. Modrá for help during the field trip to Syria. We thank V. Schacherlova for the preparation of histological and SEM samples. This study was sup- 
ported by the grant No. 524/00P015 of the Grant Agency of the Czech Republic, and in part also by the grant No. 1228/1999 of Ministry of Education.

\section{REFERENCES}

Abdel-Ghaffar F., Bashtar A. R., Ashour M. B. \& SaKran T. Life cycle of Sarcocystis gongyli Trinci 1911 in the skink Chalcides ocellatus and the snake Spalerosophis diadema. A light and electron microscopic study. Parasitology Research, 1990, 76, 444-450.

Bashtar A. R., Abdel-Ghaffar F., Ashour M. B. \& Sakran T. Endodyogony and cyst formation of Sarcocystis gongyli (Trinci 1911) from the skink Chalcides ocellatus. Journal of the Egyptian Society of Parasitology, 1991, 21, 383-393.

Bertram A. Beiträge zur Kenntnis der Sarcosporidien nebs einem Anhang über parasitische Schläuche in der Leibeshöhle von Rotatorien. Zoologische Jabrbücher. Abteilung für Anatomie und Ontogenie der Tiere, 1892, 5, 581-604.

Bledsoe B. Sarcocystis idaboensis sp. n. in deer mice Peromyscus maniculatus (Wagner) and gopher snake Pituophis melanoleucus (Daudin). Journal of Protozoology, 1980, 27, 93-102.

Box E. D., Marchiondo A. M., Duszynski D. W. \& Davis P. Ultrastructure of Sarcocystis sporocysts from passerine birds and opossums: comments on classification of the genus Isospora. Journal of Parasitology, 1980, 66, 68-74.

Chatton E. \& Avel M. Sur la Sarcosporidie du gecko et ses cytophanères. La paroi et le réticulum sarcosporidiens appartiennent en propre au parasite. Comptes Rendus des Sciences de la Société de Biologie (Paris), 1923, 89, 181-185.

Dupouy J. \& Kechemir N. Les Cestodes de reptiles en Algérie. Essai de revision du genre Oochoristica Lühe (Cestoda, Anoplocephalidae). Bulletin de la Société Histoire Naturelle d'Afrique Nord (Alger), 1973, 64, 47-98.

DASZAK P. \& Cunningham A. A report of intestinal sarcocystosis in the Bullsnake (Pituophis melanoleucus sayi) and re-evaluation of Sarcocystis sp. from snakes of the genus Pituophis. Journal of Wildlife Diseases, 1995, 31, 400-403.

MatuschKa F.-R. Life cycle of Sarcocystis between pokilothermic hosts. Lizards are intermediate hosts for $S$. podarcicolubris sp. nov., snakes function as definitive hosts. Zeitschrift für Naturforschung, 1981, 36c, 1093-1095.

MatuschKa F.-R. Experimental investigations on the host range of Sarcocystis podarcicolubris. International Journal for Parasitology, 1985, 15, 77-80.

MATUSCHKA F.-R. Sarcocystis clethrionomyelaphis n.sp. from snakes of the genus Elaphe and different voles of the family Arvicolidae. Journal of Parasitology, 1986, 72, 226-231.

MatuschKa F.-R. Reptiles as intermediate and/or final hosts of Sarcosporidia. Parasitology Research, 1987a, 73, 22-32.

MatuschKa F.-R. Sarcocystis chalcidicolubris n. sp.: Recognition of the life cycle in skinks of the genus Chalcides and snakes of the genus Coluber. Journal of Parasitology, 1987b, 73, 1014-1018.

MatuschKa F.-R. \& Mehlhorn H. Sarcocysts of Sarcocystis podarcicolubris from experimentally infected Tyrrhenian wall lizards (Podarcis tiliguerta), S. gallotiae from naturally infected Canarian lizards (Gallotia galloti) and $S$. dugesii from Madeiran lizards (Lacerta dugesii). Protistologica, 1984, 20, 133-139.

McAllister C.T., Upton S.J., Garrett C.M., Stuart J.N. \& PainTER C.W. Hemogregarines and Sarcocystis sp. (Apicomplexa) in a Western Green Rat Snake, Senticollis triaspis intermedia (Serpentes: Colubridae), from a New Mexico. Journal of the Helminthological Society of Washington, 1993, 60, 284-286.

McAllister C. T., Upton S. J., Trauth S. E. \& Dixon J. R. Coccidian parasites (Apicomplexa) from snakes in the Southcentral and Southwestern United States: new host and geographical records. Journal of Parasitology, 1995, 81, 63-68.

McAllister C.T., Upton S.J., Barker D.G. \& Painter C.W. Sarcocystis sp. (Apicomplexa) from a New Mexico Ridgenose Rattlesnake, Crotalus willardi obscurus (Serpentes: Viperidae) from Sonora, Mexico. Journal of the Helminthological Society of Washington, 1996, 63, 158-130.

ODENING K. The present state of species-systematics in Sarcocystis Lankester, 1882 (Protista, Sporozoa, Coccidia). Systematic Parasitology, 1998, 41, 209-233

PAPERNA I. \& Finkelman S. Sarcocystis infection among snakes in Israel. Parassitologia, 1998, 40, 447-456.

Roudabush R.L. Some coccidia of reptiles found in North America. Journal of Parasitology, 1937, 23, 354-359.

SAKRAN T.F.A. Sarcocystis gongyli (Sarcocystidae-Sporozoa), predator-prey monoxenous life cycle. Journal of the Egyptian German Society for Zoology, 1993, 11 (D), 91-105.

Speer C.A., Hammond D.M., Mahrt J.L. \& Robersts W.L. Structure of the oocyst and sporocyst walls and excystation of sporozoites of Isospora canis. Journal of Parasitology, 1973, 59, 35-40.

Speer C.A., Marchiondo A.A., Duszynski D.W. \& File S.K. Ultrastructure of the sporocyst wall during excystation of Isospora endocallimici. Journal of Parasitology, 1976, 62, 984-987.

ŠLAPETA J.R., MODRY D. \& KOUdELA B. Sarcocystis atheridis n. sp., a new sarcosporidian coccidium from the Nitsche's Bush Viper, Atheris nitschei Tornier, 1902 from Uganda. Parasitology Research, 1999, 85, 758-764.

Trinci G. Nota sopra una Sarcocystis parasita di Gongylus ocellatus Wagl., con considerazioni critiche sulla morfologia a sulla biologia dei Sarcosporidi. Monitore Zoologico Italiano, 1911, 22, 309-326.

Volf J., Modry D., Koudela B. \& Šlapeta J.R. Discovery of the life cycle of Sarcocystis lacertae Babudieri, 1932 (Apicomplexa: Sarcocystidae), with a species redescription. Folia Parasitologica, 1999, 46, 257-262.

WeBer A. Sur la morphologie dela Sarcosporidie du gecko (Sarcocystis platydactyli Bertram). Comptes Rendus des Sciences de la Societe de Biologie (Paris), 1909, 66, 10611062.

WeBER A. Recherches sur la Sarcosporidie du gecko (Sarcocystis platydactyli Bertram). Archives de Anatatomie Microscopique, 1910, 66, 1061-1062.

Reçu le 16 mars 2000 Accepté le 27 juin 2000 